\title{
1 Transcriptional regulation of development in heterocyst-forming
}

2 cyanobacteria

3

4

6

\section{Enrique Flores*, Silvia Picossi, Ana Valladares and Antonia Herrero Instituto de Bioquímica Vegetal y Fotosíntesis, CSIC and Universidad de Sevilla, Seville, Spain}

*E-mail address: eflores@ibvf.csic.es

\section{ABSTRACT}

Filamentous, heterocyst-forming cyanobacteria are among the simplest multicellular systems in Nature. In the absence of combined nitrogen, the filaments consist of vegetative cells that fix $\mathrm{CO}_{2}$ through oxygenic photosynthesis and micro-oxic heterocysts specialized for the fixation of $\mathrm{N}_{2}$ in a proportion of about 10 to 1 . The development of a heterocyst-containing filament involves differentiation of vegetative cells into heterocysts in a process that requires a distinct gene expression program. Two transcription factors are strictly required, the CRP-family NtcA and HetR. NtcA directly activates the expression of multiple genes during heterocyst differentiation -in some cases assisted by coactivators including HetR- and in mature heterocysts, whereas HetR is needed to build high NtcA levels in differentiating heterocysts and directly activates some particular genes. A few other regulators of gene expression participate at specific differentiation steps, and a specific transcription factor, CnfR, activates nif gene expression under the micro-oxic conditions of the heterocyst. 


\section{Introduction}

Multicellularity is a form of organization widely found in living organisms including evidently eukaryotes but also prokaryotes. Two properties characterize multicellularity: cell-cell binding and cell-cell communication. Additionally, organisms take advantage of multicellularity to specialize cells in different functions, so that cellular differentiation is another hallmark of multicellularity. Proterozoic microfossils frequently show a multicellular form, and filamentous cyanobacteria showing cellular differentiation have been traced back to about $2.45-2.1$ billion years ago [1]. Cyanobacteria are a phylogenetically coherent group of organisms characterized by performing oxygenic photosynthesis, which allows a mainly photoautotrophic mode of growth [2]. Additionally, many cyanobacteria can fix atmospheric $\mathrm{N}_{2}$, making these organisms capable to grow with very simple nutritional sources -air and water with a few mineral salts. However, because the $\mathrm{N}_{2}$-fixation machinery is very sensitive to oxygen [3], cyanobacteria need to separate $\mathrm{N}_{2}$ fixation from oxygenic photosynthesis. Whereas some unicellular and filamentous cyanobacteria separate these two incompatible processes temporally, restricting $\mathrm{N}_{2}$ fixation to the dark period of diel cycles [3], some filamentous cyanobacteria form cells specialized for $\mathrm{N}_{2}$ fixation. Thus, in filaments of cells that fix $\mathrm{CO}_{2}$ through oxygenic photosynthesis, some of these cells (usually less than $10 \%$ ) differentiate into $\mathrm{N}_{2}$-fixing heterocysts when no combined nitrogen is available [4]. Other developmental options found in some heterocyst-forming cyanobacteria include the differentiation of akinetes, a type of spores that resist drought and cold, and the production of hormogonia, short motile filaments frequently made of small-sized cells that serve a dispersal function [5, 6]. Knowledge of the transcriptional regulation for the differentiation of akinetes and hormogonia is however scarce [6]. This review will focus on the transcriptional regulatory mechanisms that operate in heterocyst differentiation. We shall first briefly introduce the structure of the cyanobacterial filament and the morphology and biochemistry of the heterocyst, then describe the mechanisms of regulation of gene expression that operate during the process of differentiation and in the mature $\mathrm{N}_{2}$-fixing heterocyst, and finally discuss the early regulation that leads to a defined pattern of heterocyst distribution in the filament.

Cyanobacteria of the order Nostocales -taxonomic section IV in the classification of Rippka et al. [2]- are characterized by their ability to produce heterocysts when they lack a source of combined nitrogen [2]. These cyanobacteria grow as filaments that can be hundreds of cells 
long, and heterocysts can be found intercalary or at the end in the filaments, although some strains make only terminal heterocysts [2]. Heterocysts are terminally differentiated cells, and commitment to complete differentiation is established after the spatial distribution pattern of heterocysts has already been settled $[7,8]$.

\subsection{Structure of the cyanobacterial filament}

The cyanobacteria are diderm bacteria, i.e., they bear a Gram-negative type of cell envelope. The cells in a cyanobacterial filament are surrounded by their cytoplasmic membrane and peptidoglycan layer(s), but the outer membrane does not enter into the septa between consecutive cells and, therefore, is continuous along the filament [9]. This implies that the periplasm -the space that lies between the cytoplasmic and outer membranes and contains the peptidoglycan- is also continuous and may be a communication conduit between the cells in the filament [10]. Consecutive cells in the filament are also joined by proteinaceous structures known as septal junctions $[9,11]$, which appear to traverse the septal peptidoglycan through perforations known as nanopores $[12,13]$. These perforations are drilled in the peptidoglycan by AmiC-type amidases $[12,14]$. In the model heterocyst-forming strain Anabaena sp. PCC 7120 (hereafter Anabaena), the SepJ (a.k.a. FraG), FraC and FraD proteins are localized the cell poles in the intercellular septa of the filament $[15,16]$. They are membrane proteins that, in the case of SepJ and FraD, have long extra-membrane sections that appear to be located outside of the cells in the intercellular septa, and at least SepJ is known to form multimers $[17,18]$. Hence, they are candidate components of the septal junctions (see below).

\subsection{Heterocyst morphology}

Under the light microscope, the heterocysts are seen larger than the vegetative cells and show two refractile bodies at their poles (just one, proximal to the vegetative cells, in the case of terminal heterocysts) (Fig. 1A). Under the electron microscope, differences become evident in the global form of the heterocyst, in its envelope, and in its cytoplasm (Fig. 1B). The heterocyst poles adjacent to vegetative cells take a narrow form known as "neck", which makes the area of contact between heterocysts and vegetative cells smaller than that between vegetative cells. The cell envelope contains extra material that is deposited outside the outer membrane and consists of an inner glycolipid (heterocyst-specific glycolipid, $\mathrm{Hgl}$ ) layer and an outer polysaccharide (heterocyst envelope polysaccharide, Hep) layer. Three characteristics distinguish the heterocyst cytoplasm from the vegetative cell cytoplasm [6]: (i) intracellular membranes are reorganized forming a structure known as "honeycomb" around the heterocyst poles; (ii) glycogen granules and carboxysomes (the intracellular micro-compartments that 
contain ribulose bisphosphate carboxylase/oxygenase [RuBis $\mathrm{CO}$, the $\mathrm{CO}_{2}$-fixing enzyme])

104 disappear; and (iii) a large granule made of cyanophycin (multi-L-arginyl-poly [L-aspartic acid])

105 is deposited at the heterocyst poles adjacent to vegetative cells -these granules correspond to 106 the refractile bodies observed by light microscopy.

\subsection{Heterocyst biochemistry}

109 The heterocyst has evolved to become a $\mathrm{N}_{2}$-fixing factory. Hence, an essential goal of its

110 biochemistry is to keep a micro-oxic environment appropriate for the expression and function

111 of the $\mathrm{N}_{2}$-fixing enzyme, nitrogenase, and accessory proteins. First, importantly, the oxygen-

112 releasing photosystem II (PSII) is non-functional in the heterocyst (reviewed in [19]). Second, the

113 extra envelope described above restricts gas diffusion contributing to reduce the amount of

114 oxygen that enters in the heterocyst as air $\left(78 \% \mathrm{~N}_{2}, 21 \% \mathrm{O}_{2}\right)$ [20]; indeed, $\mathrm{O}_{2}$ has been suggested

115 to enter the heterocyst mainly through the vegetative cell-heterocyst connections [20]. Third,

116 dedicated terminal respiratory oxidases located in the honeycomb membranes and cytoplasmic

117 flavodiiron proteins consume $\mathrm{O}_{2}$ contributing to create a micro-oxic environment [21, 22]. The

118 nitrogenase reaction consumes high amounts of ATP and reductant, and the heterocyst keeps

119 an electron transport chain and PSI activity that support photophosphorylation and the

120 reduction of ferredoxin that can provide nitrogenase with electrons [19].

121 In the heterocyst, dinitrogen is reduced by the nitrogenase complex producing

122 ammonium (and hydrogen as a byproduct). The ammonium resulting from the $\mathrm{N}_{2}$-fixing reaction

123 is incorporated by glutamine synthetase into glutamate producing glutamine [23]. Glutamine is,

124 at least in part, transferred to vegetative cells in exchange for glutamate, which is not

125 synthesized at high levels in the heterocyst [24, 25]. Further anabolic nitrogen metabolism in

126 the heterocyst includes the biosynthesis of aspartate and arginine, which are incorporated by

127 cyanophycin synthetase into cyanophycin that serves as a dynamic nitrogen reservoir [26, 27].

128 In addition to glutamine, $\beta$-aspartyl arginine, the product of cyanophycin degradation by

129 cyanophycinase, is transferred to vegetative cells, in which $\beta$-aspartyl arginine is hydrolyzed by

130 isoaspartyl dipeptidase releasing aspartate and arginine [28]. Hence, both glutamine and $\beta$ -

131 aspartyl arginine serve as nitrogenous nutrients for the vegetative cells. In turn, because the

132 heterocyst does not accomplish the photosynthetic fixation of $\mathrm{CO}_{2}$, the vegetative cells provide

133 the heterocysts with reduced carbon in the form of a sugar, sucrose, that in Anabaena is split by

134 an invertase -InvB- producing glucose and fructose, which support heterocyst metabolism [29,

135 30]. This exchange of reduced carbon by fixed nitrogen is at the basis of the multicellular

136 behavior of heterocyst-forming cyanobacteria. 


\subsection{Intercellular molecular exchange}

139 During heterocyst differentiation and in the diazotrophic filament, regulators and metabolites

140 are transferred between cells. Intercellular molecular exchange in filamentous cyanobacteria

141 has been probed with fluorescent markers including calcein, 5-carboxyfluorescein and the

142 sucrose analog esculin [13, 31,32]. The transfer has properties of simple diffusion, indicating

143 the existence of direct connections between adjacent cells [31, 32]. Mutants of Anabaena

144 lacking the septal proteins SepJ or FraC and FraD are impaired in the intercellular transfer of

145 those fluorescent markers and make less nanopores than the wild type, suggesting that these

146 proteins contribute to the formation of the septal junctions [13, 31]. Differences in the

147 impairment of transfer of the various fluorescent markers in different mutants have suggested

148 the existence of functionally-discernible SepJ- and FraCD-related septal junctions $[13,17]$.

149 Important for our discussion here is that septal junction complexes in the vegetative

150 cell/heterocyst septa may have specific characteristics as compared to those in vegetative

151 cell/vegetative cell septa. Thus, these structures appear to be longer in the former than in the

152 latter [33], and the SepJ protein visualized as a SepJ-GFP fusion is seen as a single fluorescent

153 spot between vegetative cells and as a double spot in the vegetative cell/heterocyst septa,

154 implying a more spread localization in the latter than in the former [11].

3. Key transcription factors and transcriptional regulation mechanisms

Two genes whose inactivation completely abolish heterocyst differentiation are ntcA [34, 35] and hetR [36]. Whereas NtcA is a global regulatory transcription factor of cyanobacteria mediating responses to variations in the C-to-N balance of the cells, HetR is a transcription factor specifically found in filamentous cyanobacteria whose best-known role is in cell differentiation. NtcA is a cyanobacterial transcription factor that orchestrates the genetic responses to the Cto- $\mathrm{N}$ balance by directly regulating the expression of multiple genes involved in pathways for nitrogen assimilation, but also of a number of other metabolic pathways [37, 38]. Indeed, by means of chromatin-immunoprecipitation assays performed in Anabaena, an extraordinarily large number of NtcA-binding sites on DNA were identified that could be ascribed to more than 2,000 genes [38]. Besides genes involved in nitrogen scavenging and $\mathrm{N}_{2}$ fixation, the NtcA targets 
171 and, remarkably, many predicted regulatory genes, which should extend the range of NtcA172 influenced cellular processes. NtcA belongs to the CRP (ㄷAP receptor protein) family of 173 transcriptional regulators, presenting a domain architecture similar to that of the wellcharacterized E. coli CRP protein, including an $N$-terminal $\beta$-roll fold, which in CRP accommodates the effector CAMP, a central long dimerization helix and a C-terminal helix-turnhelix (HTH) motif for interaction with DNA [39] (Fig. 2A). These regulators are dimeric proteins, so that each subunit interacts with half of a palindromic recognition sequence in DNA.

$\mathrm{NtcA}$ can act as a transcriptional activator or repressor. For both activities, the NtcA dimer binds to palindromic DNA sites including the consensus sequence $\operatorname{GTAN}_{8} \operatorname{TAC}[37,38]$. In many NtcA-activated promoters an NtcA-binding site is found separated by ca. 22 bp from a -10 promoter determinant of consensus sequence $\mathrm{TAN}_{3} \mathrm{~T}$, thus conforming to the so-called Class II bacterial activated promoters, in which the regulator binds in place of a missing or degenerated -35 determinant. This promoter structure is frequently found in genes of unicellular cyanobacteria and, in heterocyst-forming strains, in vegetative cell-expressed genes as well as in genes expressed in mature heterocysts [40]. Besides this, NtcA can activate gene expression from DNA sites centered further upstream the -35 position, conforming to Class I activated promoters, or from promoters with very degenerated NtcA-binding sites, which are generally activated during heterocyst differentiation [41]. Finally, repression by NtcA has been shown involving binding sites downstream from promoter determinants, overlapping the -10 box or even within the regulated ORF [41].

Regarding metabolic signals, NtcA activity is influenced by 2-oxoglutarate (2-OG) [42]. Because cyanobacteria lack the enzyme 2-oxoglutarate dehydrogenase, the 2-OG cellular levels depend on its synthesis during $\mathrm{CO}_{2}$ fixation and its consumption mainly to form glutamate by the glutamine synthetase/glutamate synthase pathway, thus representing an indicator of the cellular C-to-N balance [40]. Indeed, 2-OG has been shown to increase the binding of NtcA to DNA in many regulated promoters in vitro, although in contrast to CRP, NtcA can interact with

198 OG in binding is explained by its effect on dimer stabilization by decreasing the distance between 199 the dimerization helices of each subunit, which in turn repositions the two second helices in the 200 HTH DNA-binding domains, making the global conformation more suitable for interaction with 201 DNA [39]. In the absence of the effector, the NtcA apo-protein already presents in its DNA202 binding domain some exposed positively-charged residues that represent a DNA-binding patch. 203 In addition, the conformation of the last helices in this domain allows some interaction with DNA, whereas these helices are buried in the apo-CRP [39]. 
Whereas a positive effect of 2-OG on NtcA binding to DNA in vitro has been found in all types of NtcA-activated promoters, although at variable extents, an additional and stringent requirement for 2-OG has been found for the step of promoter melting to form the tripartite NtcA-RNA polymerase-DNA open promoter complex, and thus for transcript production, at Class II NtcA-activated promoters [43]. However, no specific structural information is available for this 2-OG effect, although it is reminiscent of that of cAMP during Class II activation by CRP. Finally, the intrinsic capacity of NtcA to interact with DNA may be important for its action as a repressor under physiological conditions that determine low 2-OG levels. This appears to occur in the $c m p R$ gene (encoding a LysR-type regulator of a bicarbonate transporter operon), which under conditions that determine low 2-OG levels is expressed at higher levels in an ntcA mutant than in the wild type [44].

\subsection{HetR}

For many years considered as a heterocyst-specific regulator, evidence is recently accumulating in support of HetR activity also in undifferentiated cells, consistent with the presence of HetR in non-heterocystous cyanobacteria as well as in heterocyst formers [45]. HetR is required for the expression of multiple genes involved in heterocyst differentiation, and binding of HetR to DNA from the promoter region of a few of them has been detected in vitro, including sequences from the promoters of hetR, patS and hepA ([46], see below) as well as of hetP, which has been implicated in the commitment to irreversible differentiation [47, 48]. A global study of HetR targets by chromatin immunoprecipitation identified 26 direct targets, of which only $10 \%$ are related to known heterocyst-differentiation genes [49]. Finally, a role of HetR in repression of several gene promoters in vegetative cells has been reported $[29,50,51]$.

Structurally, HetR represents a rather distinct type of transcription factor. The crystal structure of a dimer of HetR from the heterocyst-forming cyanobacterium Fischerella sp. shows a central DNA-binding region constituted by the $\mathrm{N}$-terminal HTH motifs of both subunits, and new folds conforming two globular "flaps" and a "hood" over the central core, the latter formed by the two C-terminal parts [52] (Fig. 2B). However, HetR tetramers have been detected in vivo, at higher levels during heterocyst differentiation, leading to the proposal that the tetramer represents an active form of HetR [53]. This is consistent with (i) the fact that in crystals assembled by HetR in complex with long synthetic DNA targets, HetR tetramers formed by interaction of the flap domains were the predominant form [54], and (ii) the occurrence of tandem repeats of the HetR DNA-binding consensus sequence in several of the identified HetR targets [49]. 
241 The expression of both $n t c A$ and hetR increase early during heterocyst differentiation, upon combined $\mathrm{N}$ step-down, in a mutually-dependent manner enhanced by positive autoregulation, with hetR induction preceding that of $n t c A$ [55]. Remarkably, induction takes place in specific cells or cell clusters along the filament, marking the places of vegetative cell differentiation into heterocysts ([56-58], see below). The response regulator-like factor NrrA, which is directly induced by NtcA early upon N step-down from a canonical Class II promoter [59], has been reported to bind the hetR promoter region in vitro and, hence, to mediate the induction of het $R$ by NtcA [60].

Multiple genes whose products effect the morphological and biochemical differentiation of heterocysts (see below), including secondary regulators, are also activated upon combined $\mathrm{N}$ step-down at specific steps during differentiation $[41,61]$, and for some of them induction could be ascribed to specific cells along the filament (see e.g. $[29,62])$. In contrast to nrrA, which is independent of HetR, in vivo activation of many other heterocystdifferentiation genes depends on both NtcA and HetR, as they are not induced in strains bearing inactivated ntcA or hetR genes. Mechanistically, a remarkable feature of heterocystdifferentiation genes is that they present complex promoter sequences including several successive promoters, which may include $\sigma^{70}$ consensus-type promoters, likely directing a basal level of gene expression in all the cells of the filament before $\mathrm{N}$ step-down, Class II and Class I NtcA-activated promoters, and HetR-dependent promoters (see e.g. [41, 50,63]). The binding affinity of NtcA for the different NtcA-activated promoters and the response to HetR are important in determining the temporal sequence of transcription activation during the differentiation process that, as a result of the cell-confined increase of het $R$ and $n t c A$ expression, takes place in specific cells along the filament.

HetR appears to exert a positive effect on transcription activation by several mechanisms. As mentioned above, direct binding of HetR in vitro has been reported for only a few sequences upstream of heterocyst-differentiation genes [49], suggesting that the in vivo requirement could be indirect in many promoters, e.g., by the requirement of high levels of $\mathrm{NtcA}$, attained by HetR-dependent activation of the ntcA gene, or of later secondary regulators. In the case of the proximal promoter of the $\operatorname{devBCA}$ operon involved in deposition of the $\mathrm{Hg}$ l layer (see below), HetR could not bind DNA by itself but was found to increase the binding of NtcA at degenerated NtcA-binding sequences, thus behaving as an NtcA-coactivator [50] (Fig. $2 \mathrm{C})$. On the other hand, the pipX gene, which is activated directly by NtcA at late stages of heterocyst differentiation, encodes a small protein required for full diazotrophic growth and full 
274 activation of further late genes [62]. The structure of a complex of the NtcA and PipX proteins 275 from the unicellular cyanobacterium Synechococcus elongatus has been determined, leading to 276 the suggestion that binding of PipX stabilizes the active conformation of NtcA [64]. With the 277 Anabaena proteins, PipX has been shown to increase NtcA binding to DNA and transcription 278 from NtcA-dependent promoters in vitro, thus representing a late NtcA-coactivator [65].

279 Regarding RNA polymerase sigma factors, NtcA-dependent transcription has been 280 achieved in vitro with the Anabaena RNA polymerase holoenzyme including the principal group $2811 \sigma^{70}$-family factor SigA [43]. In Anabaena, the sigA gene is transcribed from one major, proximal 282 promoter that was first described to display constant activity [66] and later to be repressed by 283 NtcA after $\mathrm{N}$ step-down [67]. Additionally, several promoters induced upon removal of 284 combined nitrogen contribute to expression of sigA. This array of promoters produces increased 285 transcription of sigA in the differentiating cells, which is consistent with a bulk of NtcA286 dependent transcription during differentiation. Further, Anabaena has multiple $\sigma^{70}$-family 287 factors of groups 2 and 3 [68]. Although inactivation of none of them abolishes heterocyst 288 differentiation or diazotrophic growth, some of the single and double mutants that have been isolated are affected in these processes [69]. Also, the sigC (group 2), sigE (group 2) and sigG 290 (group 3) genes are responsive to $\mathrm{N}$ step-down, with successive increases of expression in the 291 cells that are differentiating into heterocysts [70]. SigE is upregulated late during differentiation, 292 and both NrrA [71] and NtcA [72] directly bind to sequences upstream of sigE. SigE is required 293 for normal cellular differentiation and for expression of several heterocyst-specific genes 294 including nifH (encoding a nitrogenase subunit), $f d x H$ (encoding a putative electron donor to 295 nitrogenase [73]), $h g / E_{2}$ (encoding a heterocyst-specific glycolipid biosynthesis protein [72]), and 296 the xfp operon involved in glycolysis [71]. Thus, in spite of considerable redundancy, a 297 succession of specific $\sigma^{70}$-family factors appears to cooperate with SigA during heterocyst 298 differentiation.

299 Finally, HetR is a target of phosphorylation in vitro and phosphorylation interferes with 300 the formation of HetR tetramers and HetR binding to DNA [53]. Consistently, overexpression in 301 Anabaena of a heterocyst-specific kinase, PknE, blocks heterocyst differentiation in a process 302 that appears to involve inactivation of HetR [74]. The pknE gene is induced late during 303 differentiation [61] with a direct participation of HetR [74] and NtcA [38], the latter using a 304 putative Class II promoter. These independent, in vitro and in vivo observations strongly suggest 305 that phosphorylation of HetR is a physiological process, leading to the proposal that 306 phosphorylation represents a mechanism of HetR inactivation at late stages of heterocyst 307 differentiation, when a direct action of HetR would be no longer required [53, 74]. 


\section{Regulation of gene expression in the course of heterocyst} differentiation

313 The expression of genes involved in heterocyst differentiation and function is generally 314 dependent on NtcA and HetR. Although regulation by these transcription factors may in some 315 cases be indirect, evidence for direct regulation, especially by NtcA, is also available for many 316 genes. Additionally, a number of other regulators, some of them transcription factors, have been 317 shown to be involved in the expression of genes at specific stages of heterocyst differentiation.

\subsection{Biosynthesis and deposition of the heterocyst envelope}

Key steps in the morphological and metabolic differentiation of heterocysts are the deposition of the Hep and Hgl layers. During differentiation, the Hep layer is deposited before the Hgl layer, allowing the latter to lie beneath the former.

\subsubsection{Hep layer}

In the chromosome of Anabaena, numerous genes involved in Hep layer formation are clustered in a "gene expression island", which covers ORFs alr2825 to alr2841 [75], and are induced under nitrogen deprivation [76]. Because they are tightly packed together, the genes alr2825 to alr2831 might constitute an operon, as might be the case for the genes alr2835 (hepA) to alr2841 as well [61]. In spite of the presence of numerous NtcA binding sites in this region [38], direct NtcA-activated expression has not been reported. On the other hand, induction in response to nitrogen deprivation of the hepA gene within this cluster requires HetR [56], which binds to a DNA fragment from the hepA promoter [46]. Direct regulation of hepA by HetR establishes a link between formation of the Hep layer and the developmental cascade of gene regulation that operates heterocyst differentiation (Fig. 3).

Expression of hepA is additionally dependent on HepK, a protein-histidine kinase of a twocomponent regulatory system that shows homology to bacterial proteins involved in acclimation to changing $\mathrm{O}_{2}$ conditions [77]. Interestingly, a normal oxic atmosphere is required for differentiation of mature heterocysts [78], but it remains to be determined whether HepK actually mediates a response to $\mathrm{O}_{2}$. A cognate response regulator of HepK is DevR [79], which can be phosphorylated but lacks a C-terminal effector domain (RR* in Fig. 3). This suggests that HepK/DevR participate in a phosphorelay transduction pathway that includes further protein components, in particular a possible DNA binding protein [80]. 
Three additional putative regulatory genes that are required for production of the Hep

344 layer are hepN (alr0117) that encodes a histidine kinase that lacks a sensor domain (HK* in Fig.

345 3) [81, 82], hepS (all2760) that encodes a putatively membrane-anchored Ser-Thr kinase [82],

346 and henR (alr1086) that encodes a response regulator containing a CheY-like receiver domain

347 and a PPM-type (magnesium or manganese-dependent protein phosphatase that

348 dephosphorylates Ser and Thr residues) phosphatase domain [82]. The effect of inactivation of

349 some of these genes on global gene expression in Anabaena -analyzed with oligonucleotide

350 microarrays- has suggested that HepS and HenR belong to the same regulatory system, and that

351 HepN is part of the HepK/DevR regulatory pathway as well as of another undetermined pathway

352 [83]. To which environmental cues the HepS kinase and the HenR phosphatase respond is

353 unknown, although expression of hepS is activated under nitrogen deprivation [61].

354 In summary, genes involved in formation of the Hep layer are subjected to regulation

355 within the cascade of gene expression that operates during heterocyst differentiation promoted

356 at least by HetR, but also to pathway-specific regulation involving two-component regulatory

357 system(s) and protein kinases/phosphatases. A main goal of future research should be to find

358 out whether any of these pathway-specific regulators responds to oxygen, and a point of general

359 interest is whether any of them are subjected to direct NtcA/HetR-dependent regulation.

\subsubsection{Hgl layer}

For a detailed discussion of the heterocyst envelope $\mathrm{Hgl} \mathrm{layer,} \mathrm{the} \mathrm{excellent} \mathrm{review} \mathrm{of} \mathrm{Awai} \mathrm{et} \mathrm{al}$

363 [84] is recommended. As is the case for the Hep layer, numerous genes involved in the formation

364 of the $\mathrm{Hgl}$ layer are clustered in the chromosome of Anabaena (ORFs all5341 to all5359),

365 including genes involved in the biosynthesis of the glycolipids and genes involved in their

366 deposition outside of the outer membrane $[85,86]$. Further genes necessary for the formation

367 of the $\mathrm{Hgl}$ layer are located outside this cluster, and these include the $\operatorname{devBCA}$ operon encoding

368 and $A B C$ exporter that, together with a TolC-like protein ( $\mathrm{GgdD})$, constitutes a Type I secretion

369 system involved in the export of glycolipids outside of the outer membrane in the differentiating

370 heterocyst [87]. Along the $\mathrm{Hgl}$ cluster, NtcA binds to several sites, including sites upstream of

371 genes all5341 (hg/T) and asr5350 as well as in the region between all5347 and all5348, which

372 could constitute activator sites [38]. On the other hand, as described above, the promoter of

373 the $\operatorname{devBCA}$ operon is a well-characterized, complex NtcA-dependent promoter [50, 88, 89]. It

374 contains one canonical Class II NtcA-activated promoter and one non-canonical promoter that 375 appears to be activated by NtcA assisted by HetR [50].

376 Inactivation of the hepS and henR genes involved in formation of the Hep layer also 377 down-regulates expression of genes involved in the formation of the $\mathrm{Hgl}$ layer such as $h g / E_{A}$ 
378 (alr5351) [83]. On the other hand, DevH is a CRP-family transcriptional regulator whose

379 expression is increased under nitrogen deprivation in an NtcA- and HetR-dependent mode [90].

380 Inactivation of $\mathrm{devH}$ affects specifically the expression of $\mathrm{Hgl}$-biosynthesis genes such as $h g / E_{A}$ 381 and the production of $\mathrm{Hgl}$ [91]. Whether HepS/HenR and DevH act in concert in the regulation 382 of expression of $h g /$ genes is unknown (discussed in [83]). Anabaena has two heterocyst-specific 383 glycolipids. Production of the minor one appears to be dependent also on two Ser/Thr kinases, 384 Pkn44 (All1625) and Pkn30 (All3691) [92], and production of the major one appears to be dependent on a specific protein phosphatase, PrpJ1 (All1731), that also affects expression of $h g / E_{A}$ [93]. The possibility that PKn44/Pkn30 and PrpJ1 belong to two different regulatory branches for production of the minor and major Hgls, respectively, acting downstream of DevH has been discussed [92].

In summary, expression of genes for the formation of the $\mathrm{Hgl}$ layer involves transcription factors including the well-known NtcA and HetR proteins discussed above and DevH. In the case of DevH, the mechanism of dependence on NtcA and HetR and the direct DNA targets remain to be elucidated. Additionally, protein kinases and phosphatases affect the formation of the $\mathrm{Hgl}$ layer as a whole and specifically the major and minor glycolipids of that layer. The environmental cues to which such kinases and phosphatases respond and how they affect glycolipid production remain to be determined (e.g., they could affect transcription factors or directly the activity of biosynthetic enzymes).

\subsection{Oxygen-consuming enzymes and protection against ROS}

399 Oxygen that enters the heterocyst is reduced by at least two types of enzymatic processes:

400 respiration [4] and reduction by flavodiiron proteins [94]. Additionally, a ruberythrin, RbrA, 401 protects against oxidative stress in the heterocyst [95]. In Anabaena, two terminal respiratory 402 oxidases, Cox2 and Cox3, substitute in the heterocyst for the terminal respiratory oxidase, Cox1, 403 expressed in vegetative cells [21]. Cox2 is an $a a_{3}$-type cytochrome $c$ oxidase encoded by the 404 coxB2-coxA2-coxC2 operon and Cox3 appears to be an heme-copper quinol oxidase that is 405 encoded by the alr2729-alr2730-coxB3-coxA3-coxC3 operon. The contribution of Cox3 to 406 protection of nitrogenase appears to be more important than that of Cox2 [21, 96]. The 407 expression of both operons is strictly dependent on NtcA and HetR. The cox3 promoter region 408 has been characterized in detail and found to contain both Class I and Class II NtcA-dependent 409 promoters in which NtcA appears to work assisted by PipX [65].

$410 \quad$ Flavodiiron proteins directly reduce $\mathrm{O}_{2}$ to water without the production of deleterious 411 reactive oxygen species (ROS) [97]. In Anabaena, two flavodiiron proteins, Flv1B and Flv3B, are 
412 specifically expressed in the heterocysts [94], being Flv3B especially relevant for diazotrophic

413 performance [22]. These flavodiiron proteins are the products of two contiguous genes, all0178

414 (Flv3B) and all0177 (Flv1B), which may constitute an operon expressed from an NtcA-dependent 415 promoter [38].

416 Interestingly, scavenging of $\mathrm{O}_{2}$ by terminal respiratory oxidases and flavodiiron proteins 417 appears not to be redundant [38]. Whereas the terminal respiratory oxidases likely remove $\mathrm{O}_{2}$ 418 in the heterocyst poles, since respiratory activity is located at the honeycomb membrabes [98], 419 the heterocyst falvodiiron proteins are cytoplasmic [94]. Photosystem I-generated reductants 420 can also reduce $\mathrm{O}_{2}$, but in this case producing ROS. In Anabaena, the rubrerythrin RbrA is a heterocyst-specific peroxidase that transfers electrons from $\mathrm{NADPH}$ to $\mathrm{H}_{2} \mathrm{O}_{2}$ with the participation of ferredoxin-NADP ${ }^{+}$oxidoreductase [95]. The rbrA gene is expressed from two promoters one of which directs expression in the heterocysts, is dependent on HetR and binds HetR in vitro [95].

\subsection{Particular heterocyst metabolism genes}

The metabolism of the heterocyst is focused on the fixation of $\mathrm{N}_{2}$ and the assimilation of the $\mathrm{N}$ fixed in that reaction. We shall address now the transcriptional regulation of nif genes and of nitrogen assimilation genes such as those encoding glutamine synthetase and cyanophycin metabolism enzymes, as well as other relevant genes.

\subsection{1. nif gene expression}

In diazotrophic bacteria, the nitrogenase structural genes, nifH-nifD-nifK, are generally clustered together with other nitrogen fixation genes -including, e.g., genes encoding nitrogenase electron donors such as specific ferredoxins- and nitrogenase maturation genes -such as FeMocofactor biosynthesis genes (99). The Anabaena genome bears a large nif gene cluster including nifB-fdxN-nifS-nifU-nifH-nifD-nifK-nifE-nifN-nifX and a few other genes downstream. Notably, $f d x N$ and nifD are interrupted by long DNA elements that are excised during heterocyst differentiation [100]. After excision, the nifHDK operon is mainly expressed from a promoter

440 located upstream from nifB [101], although the large mRNA produced is subjected to processing 441 so that nifHDK, nifHD and nifH transcripts are produced (see e.g. [96]). In Anabaena and other 442 diazotrophic cyanobacteria, including non-heterocystous strains, the nifB promoter is activated 443 by CnfR [102], previously known as PatB [103]. The CnfR protein has $\mathrm{N}$-terminal sequences for 444 binding two 4Fe-4S clusters, resembling bacterial-type ferredoxins, and a C-terminal HTH motif 445 for binding to DNA $[103,104]$. It is thought that CnfR can activate nif gene expression in response 
to a low-oxygen tension $[104,105]$, and putative CnfR-binding sites have been characterized in

447 the promoter region of $\operatorname{nifB}[105,106]$.

448 In Anabaena, expression of $c n f R(p a t B)$ is induced in response to nitrogen deprivation $449[61,103]$, exclusively in heterocysts [107]. Based on the presence of consensus NtcA-binding 450 sites upstream of $c n f R$, it can be suggested that this gene is subjected to NtcA-dependent expression in both heterocyst-forming and $\mathrm{N}_{2}$-fixing, non-heterocystous cyanobacteria [38, 105]. Anabaena variabilis harbors two nif gene clusters, nif1 that is expressed in the heterocysts and nif2 that is expressed in the vegetative cells under micro-oxic conditions (see e.g. [106]), and expression of the nif2 cluster regulatory gene cnfR2 has been shown to require NtcA [104]. Therefore, expression of $c n f R 2$ is activated when combined nitrogen is scarce, but the Fe-S clusters may be formed only when the oxygen tension is low resulting in a protein that can promote expression of the nifB operon only under micro-oxic conditions [104, 105].

\subsubsection{Expression of petH}

The petH gene encodes ferredoxin-NADP ${ }^{+}$oxidoreductase that is expressed at much higher levels in heterocysts than in vegetative cells [108], consistent with a very relevant role of this enzyme in the distribution of electrons in the heterocyst [19]. In heterocysts, petH is expressed from an NtcA-dependent promoter to which NtcA directly binds [109]. No good NtcA-binding site is however found in this promoter, suggesting the involvement of an NtcA coactivator such as PipX.

\subsubsection{Expression of $g \ln A$}

Glutamine synthetase, which incorporates into glutamate the ammonium produced in the $\mathrm{N}_{2}$ fixation reaction to synthesize glutamine, is present at higher levels in the heterocysts than in vegetative cells [110]. The gInA gene encoding glutamine synthetase is expressed at higher levels in the absence than in the presence of combined nitrogen, being transcribed from a complex promoter region [111]. The promoter most proximal to the gene is a Class II NtcA-dependent promoter that is used during growth with nitrate and under deprivation of combined $N[34,35]$. This is the $g \operatorname{InA}$ promoter that is used in the heterocysts, and its dependence on NtcA has been corroborated by mutation of its NtcA-binding site [112].

\subsubsection{Cyanophycin metabolism genes}

478 As mentioned earlier, the dynamic $\mathrm{N}$ reservoir cyanophycin is accumulated conspicuously at the heterocyst poles. In Anabaena, the genes encoding the main cyanophycin synthetase (all3879, 
cphA1) and cyanophycinase (all3880, cphB1) are clustered together. These genes are expressed as an operon ( $c p h B 1-c p h A 1)$ from a complex promoter region localized upstream of $c p h B 1$, and cphA1 is also transcribed monocistronically from a complex promoter present in the intergenic region. In these regions, NtcA-dependent promoters comprising high- and low-affinity NtcAbinding sites are found which are active in heterocysts [113]. The gene all3922, encoding isoaspartyl dipeptidase that hydrolyzes the dipeptide $\beta$-aspartyl arginine, is induced under nitrogen deprivation [61] and is expressed preferentially in vegetative cells [28], consistent with the transfer of the dipeptide from the heterocysts to the vegetative cells.

\subsubsection{Expression of RuBisCO}

As mentioned earlier, the RuBisCO enzyme is not active in the heterocysts thus avoiding the investment of energy and reductant in the fixation of $\mathrm{CO}_{2}$, a process confined to the vegetative cells. Lack of RuBisCO in the heterocysts results from repression of gene expression [114], and binding of NtcA to a DNA site overlapping the translation start of the $r b c L X S$ operon encoding RuBisCO appears to represent a mechanism of repression $[38,115]$. This mechanism of cellspecific repression of RuBisCO stresses the relevant role of NtcA in regulation of gene expression, not only by induction but also by repression, in the mature heterocyst.

\section{Heterocyst patterning}

Heterocyst distribution is not random in the cyanobacterial filaments, but instead it follows a relatively fixed pattern. In most strains of the order Nostocales, heterocysts are separated by ca. 10 to 15 vegetative cells along the filament. Importantly, this pattern is established early upon $\mathrm{N}$ step-down, implying that products of $\mathrm{N}_{2}$ fixation are not required for generation of at least the initial pattern.

\subsection{Coupled fluctuations of HetR expression}

507 Several theoretical models have been put forward to try a mathematical description of the generation of the heterocyst distribution pattern, and most of those models are based on the operation of an activator and an inhibitor of differentiation with different intercellular

510 diffusivities (revised in [116]). The HetR transcription factor has been considered as the activator

511 in these models. As mentioned above, basal expression of het $R$ takes place in the filament even

512 in the presence of ammonium, and expression fluctuations are coupled in 2-4 nearby cells

513 influenced by positive autoregulation ([117]; J. Stavans, personal communication). Moreover, 
514 this pattern persists during the initial stages of development upon $\mathrm{N}$ step-down [117], which

515 could explain the classical observation that differentiation is first observed in small clusters of

516 cells that are later resolved to single heterocysts [8]. Thus, coupled fluctuations of hetR

517 expression after $\mathrm{N}$ step-down would build-up upon the basic pattern already latent under $\mathrm{N}$ -

518 replete conditions. At intermediate stages of differentiation, an increase in autocorrelation

519 functions of hetR expression is observed [117], which would result from increased hetR

520 autoregulation in response to $n t c A$ (and $n r r A$ ) induction.

523 The pats gene is induced early in specific cells, depending on HetR [46], and its overexpression

524 abolishes heterocyst differentiation, whereas its inactivation leads to the formation of 525 heterocysts in groups (the so called $\mathrm{MCH}$, multiple contiguous heterocysts phenotype). Hence, 526 it was suggested that a patS gene product effects a lateral inhibition of differentiation [118]. The 527 primary product of the patS gene is a 17-amino acid peptide that is processed to render a smaller 528 active peptide including the C-terminal part of the primary gene product $[118,119]$, likely 529 consisting of the C-terminal seven residues $[119,120]$. Nonetheless, a peptide consisting of only 530 the five C-terminal amino acids of PatS can also suppress heterocyst differentiation when added 531 to Anabaena cultures [118]. The active PatS peptide (which we will denote hereafter PatS*) is 532 transferred to the neighboring cells to establish a concentration gradient with highest levels in 533 the cells adjacent to the producing cell, in which the concentration remains negligible, and 534 decreasing thereon, thus behaving as a morphogen [119]. The N-terminal half of the patS 535 primary product is important for processing of the peptide and for conferring immunity against 536 the inhibitory activity in the producing cell, which would involve peptide excretion [119].

537 The hetC gene encodes an ABC-type exporter that includes a putative peptidase domain 538 required for heterocyst differentiation [121, 122]. hetC is expressed from a complex promoter 539 region that includes a canonical NtcA-dependent promoter and a HetR- and NtcA-dependent 540 promoter, similar to the promoter region of the $\operatorname{devBAC}$ operon $[43,89]$. HetC localizes mostly 541 to the heterocyst poles [122], and the possibility of its involvement in export of PatS* from the 542 differentiating heterocysts has been considered [122, 123], as has also been considered the 543 participation of the septal junction protein SepJ in the intercellular transfer of PatS* between 544 vegetative cells [124]. Regarding the inhibitory activity of the morphogen, PatS* has been shown 545 to interact with HetR $[125,126]$, to influence the turnover of HetR [127], and to inhibit HetR 546 tetramer accumulation [53] and HetR binding to DNA [46]. All these observations are fully 547 consistent with the reported isolation of a suppressor mutant of patS overexpression, which 548 bore a mutation in the hetR gene [128]. Thus, at least one component of the inhibition of 
549 heterocyst differentiation by PatS* is the inhibition of HetR activity. Figure 4 presents a

550 hypothetical model in which (i) HetC participates in processing of PatS and transfer of PatS*

551 from the (pro)heterocyst to its neighboring vegetative cell, and (ii) SepJ participates in spreading

552 of PatS* between vegetative cells along the filament. How PatS* is prevented from moving back

553 to the (pro)heterocyst through SepJ-related conduits is unknown, but may be related to the

554 distinct architecture of the septal junctions in vegetative cell-heterocyst septa described above.

555 Besides being dependent on hetR auto-regulation, the spatial correlation of hetR

556 expression fluctuations along the filament, both in the presence of ammonium and early after

$557 \mathrm{~N}$ step-down, is influenced by expression of pats and intercellular communication dependent

558 on SepJ [117]. This implies the existence of a basal expression of patS in the presence of

559 ammonium, consistent with the reported detection of pats transcription in the presence of

560 combined nitrogen [8]. Thus, fluctuations in the expression of het $R$ encoding a positive regulator

561 of differentiation, HetR positive autoregulation, lateral inhibition by PatS (whose synthesis

562 depends on HetR), and cell-to-cell communication are fundamental components of the

563 developmental process.

\subsection{Other proteins influencing pattern formation}

566 Finally, other protein factors -including HetL, HetN, PatA, PatL and PatN- have been described to influence the spatial pattern of heterocyst distribution. The het $N$ gene influences the pattern of heterocysts especially at advanced stages of differentiation $[129,130]$. This effect likely involves an internal hexapeptide sequence identical to the C-terminal sequence of PatS [130,

570 131]. Indeed, at late, but not at early times after $N$ step-down, expression of het $N$ has been 571 shown to influence the coupling of hetR expression fluctuations through the filament [117]. At

572 times when heterocyst differentiation is already completed, the FraC/FraD proteins involved in

573 intercellular molecular exchange impact hetR expression correlations in neighboring cells in a

574 manner similar to SepJ [117]. This effect of FraC/FraD could involve transfer of a HetN-derived

575 product or other regulators or $\mathrm{N}_{2}$ fixation-derived metabolites.

576 Whereas inactivation of patN results in an increased heterocyst frequency [132, 133],

577 inactivation of patA [134] or patL [135] results in the preferential production of terminal

578 heterocysts in the filaments (implying a decreased heterocyst frequency). On the other hand,

579 overexpression of hetL increases heterocyst frequency [136]. PatL and HetL are pentapeptide

580 repeat proteins of unknown function, PatA and PatL have been shown to interact with each 581 other [135], and PatN has been shown to influence the expression of patA [132]. Significantly, 582 the patA gene is transcribed in differentiating heterocysts from two NtcA-activated promoters 
[137]. PatA is a response regulator that lacks a DNA binding domain and counteracts PatS and

584 HetN inhibition of heterocyst differentiation [138].

\section{Concluding remarks}

Heterocyst differentiation from a vegetative cell involves changes in expression of several hundred genes [139], including repression and induction (thoroughly reviewed by Xu et al. [140]). Several transcription factors effecting this regulation have been identified mainly in the model organism Anabaena (Table 1). NtcA and HetR are absolutely needed for heterocyst differentiation, whereas other transcription factors participate in specific steps of the differentiation process. NtcA and HetR are however not equivalent. Whereas NtcA is a global transcription factor that activates numerous gene promoters at different steps of differentiation, and represses some promoters as well, HetR has been shown to bind to few DNA sequences possibly activating transcription. Additionally, the strict requirement for HetR may rely on (i) its effect on localized induction of $n t c A$ in the developing heterocyst and (ii) a role as a coactivator of NtcA at specific promoters. An additional coactivator of NtcA is PipX, which being expressed late in heterocyst differentiation supports NtcA-dependent activation of late genes, including some that are expressed in mature heterocysts. In the mature heterocyst, the $r b c L$ operon promoter is directly repressed by NtcA, and a highly-expressed gene such as $g \ln A$ is transcribed from a canonical Class II NtcA-dependent promoter, raising the possibility that expression in the mature heterocyst no longer requires differentiation-specific transcription factors. This is consistent with an inactivation of HetR by phosphorylation as discussed above. Finally, in the mature heterocyst, expression of the nif genes requires a specific transcription factor (CnfR) that may link expression to the micro-oxic conditions prevailing in the differentiated cell.

608

\section{Acknowledgements}

610

611 Work in the authors' laboratory is currently funded by grants number BFU2014-56757-P and

612 BFU2017-88202-P (E.F.) and BFU2016-77097-P (AH) from Agencia Estatal de Investigación, 613 Spain, co-financed by the European Regional Development Fund.

614 
[1] Tomitani A, Knoll AH, Cavanaugh CM, Ohno T, The evolutionary diversification of cyanobacteria: molecular-phylogenetic and paleontological perspectives., Proc Natl Acad Sci USA 103 (2006) 54427.

[2] Rippka R, Deruelles J, Waterbury JB, Herdman M, Stanier RY, Generic assignments, strain histories and properties of pure cultures of cyanobacteria, J Gen Microbiol 111 (1979) 1-61

[3] Gallon JR, The oxygen sensitivity of nitrogenase: a problem for biochemists and micro-organisms, TIBS 6 (1981) 19-23

[4] Fay P, Oxygen relations of nitrogen fixation in cyanobacteria, Microbiol Rev 56 (1992) 340-73.

[5] Flores E, Herrero A, Compartmentalized function through cell differentiation in filamentous cyanobacteria, Nat Rev Microbiol 8 (2010) 39-50.

[6] Maldener I, Summers ML, Sukenik A, Cellular differentiation in filamentous cyanobacteria, in: Flores E, Herrero A (Eds.) The Cell Biology of Cyanobacteria, Caister Academic Press, Norfolk, UK (2014) pp. 263-291.

[7] Bradley S, Carr NG, Heterocyst and nitrogenase development in Anabaena cylindrica, J Gen Microbiol 96 (1976) 175-84.

[8] Yoon HS, Golden JW, PatS and products of nitrogen fixation control heterocyst pattern, J Bacteriol 183 (2001) 2605-13.

[9] Wilk L, Strauss M, Rudolf M, Nicolaisen K, Flores E, Kühlbrandt W, Schleiff E, Outer membrane continuity and septosome formation between vegetative cells in the filaments of Anabaena sp. PCC 7120, Cell Microbiol 13 (2011) 1744-54.

[10] Mariscal V, Herrero A, Flores E, Continuous periplasm in a filamentous, heterocyst-forming cyanobacterium, Mol Microbiol 65 (2007) 1139-45.

[11] Flores E, Herrero A, Forchhammer K, Maldener I, Septal junctions in filamentous heterocyst-forming cyanobacteria, Trends Microbiol 24 (2016) 79-82.

[12] Lehner J, Berendt S, Dörsam B, Pérez R, Forchhammer K, Maldener I, Prokaryotic multicellularity: a nanopore array for bacterial cell communication, FASEB J 27 (2013) 2293-300.

[13] Nürnberg DJ, Mariscal V, Bornikoel J, Nieves-Morión M, Krauß N, Herrero A, Maldener I, Flores E, Mullineaux $\mathrm{CW}$, Intercellular diffusion of a fluorescent sucrose analog via the septal junctions in a filamentous cyanobacterium, mBio 6 (2015) e02109.

[14] Bornikoel J, Carrión A, Fan Q, Flores E, Forchhammer K, Mariscal V, Mullineaux CW, Perez R, Silber N, Wolk CP, Maldener I, Role of two cell wall amidases in septal junction and nanopore formation in the multicellular cyanobacterium Anabaena sp. PCC 7120, Front Cell Infect Microbiol 7 (2017) 386.

[15] Flores E, Pernil R, Muro-Pastor AM, Mariscal V, Maldener I, Lechno-Yossef S, Fan Q, Wolk CP, Herrero A, Septum-localized protein required for filament integrity and diazotrophy in the heterocystforming cyanobacterium Anabaena sp. strain PCC 7120, J Bacteriol 189 (2007) 3884-90.

[16] Merino-Puerto V, Mariscal V, Mullineaux CW, Herrero A, Flores E, Fra proteins influencing filament integrity, diazotrophy and localization of septal protein SepJ in the heterocyst-forming cyanobacterium Anabaena sp., Mol Microbiol 75 (2010) 1159-70.

[17] Merino-Puerto V, Schwarz H, Maldener I, Mariscal V, Mullineaux CW, Herrero A, Flores E, FraC/FraDdependent intercellular molecular exchange in the filaments of a heterocyst-forming cyanobacterium, Anabaena sp., Mol Microbiol 82 (2011) 87-98.

[18] Ramos-León F, Mariscal V, Battchikova N, Aro EM, Flores E, Septal protein SepJ from the heterocystforming cyanobacterium Anabaena forms multimers and interacts with peptidoglycan, FEBS Open Bio 7 (2017) 1515-1526.

[19] Magnuson A, Cardona T, Thylakoid membrane function in heterocysts. Biochim Biophys Acta 1857 (2016) 309-19. 
664

665

666

667

668

669

670

671

672

673

674

675

676

677

678

679

680

681

682

683

684

685

686

687

688

689

690

691

692

693

694

695

696

697

698

699

700

701

702

703

704

705

706

707

708

709

710
[20] Walsby AE, Cyanobacterial heterocysts: terminal pores proposed as sites of gas exchange, Trends Microbiol 15 (2007) 340-9.

[21] Valladares A, Herrero A, Pils D, Schmetterer G, Flores E, Cytochrome $c$ oxidase genes required for nitrogenase activity and diazotrophic growth in Anabaena sp. PCC 7120, Mol Microbiol 47 (2003) 1239-49.

[22] Ermakova M, Battchikova N, Richaud P, Leino H, Kosourov S, Isojärvi J, Peltier G, Flores E, Cournac L, Allahverdiyeva $Y$, Aro EM, Heterocyst-specific flavodiiron protein Flv3B enables oxic diazotrophic growth of the filamentous cyanobacterium Anabaena sp. PCC 7120, Proc Natl Acad Sci USA 111 (2014) 11205-10.

[23] Wolk CP, Thomas J, Shaffer PW, Austin SM, Galonsky A, Pathway of nitrogen metabolism after fixation of ${ }^{13} \mathrm{~N}$-labeled nitrogen gas by the cyanobacterium, Anabaena cylindrica, J Biol Chem 251 (1976) 5027-34.

[24] Thomas J, Meeks JC, Wolk CP, Shaffer PW, Austin SM, Formation of glutamine from $\left[{ }^{13} \mathrm{~N}\right]$ ammonia, $\left[{ }^{13} \mathrm{~N}\right]$ dinitrogen, and $\left[{ }^{14} \mathrm{C}\right]$ glutamate by heterocysts isolated from Anabaena cylindrica, J Bacteriol 129 (1977) 1545-55.

[25] Martín-Figueroa E, Navarro F, Florencio FJ, The GS-GOGAT pathway is not operative in the heterocysts. Cloning and expression of $\mathrm{glsF}$ gene from the cyanobacterium Anabaena sp. PCC 7120, FEBS Lett 476 (2000) 282-6.

[26] Sherman DM, Tucker D, Sherman LA, Heterocyst development and localization of cyanophycin in $\mathrm{N}_{2-}^{-}$ fixing cultures of Anabaena sp. PCC 7120 (Cyanobacteria), J Phycol 36 (2000) 932-941.

[27] Herrero A, Burnat M, Cyanophycin, a cellular nitrogen reserve material, in: Flores E, Herrero A (Eds.) The Cell Biology of Cyanobacteria, Caister Academic Press, Norfolk, UK (2014) pp. 211-219.

[28] Burnat M, Herrero A, Flores E, Compartmentalized cyanophycin metabolism in the diazotrophic filaments of a heterocyst-forming cyanobacterium, Proc Natl Acad Sci USA 111 (2014) 3823-8.

[29] López-Igual R, Flores E, Herrero A, Inactivation of a heterocyst-specific invertase indicates a principal role of sucrose catabolism in heterocysts of Anabaena sp., J Bacteriol 192 (2010) 5526-33.

[30] Vargas WA, Nishi CN, Giarrocco LE, Salerno GL, Differential roles of alkaline/neutral invertases in Nostoc sp. PCC 7120: Inv-B isoform is essential for diazotrophic growth, Planta 233 (2011) 153-62.

[31] Mullineaux CW, Mariscal V, Nenninger A, Khanum H, Herrero A, Flores E, Adams DG, Mechanism of intercellular molecular exchange in heterocyst-forming cyanobacteria, EMBO J 27 (2008) 1299-308.

[32] Nieves-Morión M, Mullineaux CW, Flores E, Molecular diffusion through cyanobacterial septal junctions, mBio 8 (2017) e01756-16.

[33] Omairi-Nasser A, Mariscal V, Austin JR 2nd, Haselkorn R, Requirement of Fra proteins for communication channels between cells in the filamentous nitrogen-fixing cyanobacterium Anabaena sp. PCC 7120, Proc Natl Acad Sci USA 112 (2015) E4458-64.

[34] Frías JE, Flores E, Herrero A, Requirement of the regulatory protein NtcA for the expression of nitrogen assimilation and heterocyst development genes in the cyanobacterium Anabaena sp. PCC 7120, Mol Microbiol 14 (1994) 823-32.

[35] Wei TF, Ramasubramanian TS, Golden JW, Anabaena sp. strain PCC 7120 ntcA gene required for growth on nitrate and heterocyst development, J Bacteriol 176 (1994) 4473-82.

[36] Buikema WJ, Haselkorn R, Characterization of a gene controlling heterocyst differentiation in the cyanobacterium Anabaena 7120, Genes Dev 5 (1991) 321-30.

[37] Luque I, Flores E, Herrero A, Molecular mechanism for the operation of nitrogen control in cyanobacteria, EMBO J 13 (1994) 2862-9.

[38] Picossi S, Flores E, Herrero A, ChIP analysis unravels an exceptionally wide distribution of DNA binding sites for the NtcA transcription factor in a heterocyst-forming cyanobacterium, BMC Genomics 15 (2014) 22. 
[39] Zhao MX, Jiang YL, He YX, Chen YF, Teng YB, Chen Y, Zhang CC, Zhou CZ, Structural basis for the allosteric control of the global transcription factor NtcA by the nitrogen starvation signal 2oxoglutarate, Proc Natl Acad Sci USA 107 (2010) 12487-92.

[40] Luque I, Forchhammer K, Nitrogen assimilation and C/N balance sensing, in: Herrero A, Flores E (Eds.) The Cyanobacteria: Molecular Biology, Genomics and Evolution, Caister Academic Press, Norfolk, UK (2008) pp. 335-382.

[41] Herrero A, Picossi S, Flores E, Gene expression during heterocyst differentiation, Adv Bot Res 65 (2013) 281-329.

[42] Vázquez-Bermúdez MF, Herrero A, Flores E, 2-Oxoglutarate increases the binding affinity of the NtcA (nitrogen control) transcription factor for the Synechococcus glnA promoter, FEBS Lett 512 (2002) 71-4.

[43] Valladares A, Flores E, Herrero A, Transcription activation by NtcA and 2-oxoglutarate of three genes involved in heterocyst differentiation in the cyanobacterium Anabaena sp. strain PCC 7120, J Bacteriol 190 (2008) 6126-33.

[44] López-Igual R, Picossi S, López-Garrido J, Flores E, Herrero A, N and C control of ABC-type bicarbonate transporter $\mathrm{Cmp}$ and its LysR-type transcriptional regulator $\mathrm{CmpR}$ in a heterocyst-forming cyanobacterium, Anabaena sp., Environ Microbiol 14 (2012) 1035-48.

[45] Zhang JY, Chen WL, Zhang CC, hetR and patS, two genes necessary for heterocyst pattern formation, are widespread in filamentous nonheterocyst-forming cyanobacteria, Microbiology 155 (2009) 1418-26.

[46] Huang $X$, Dong $Y$, Zhao J, HetR homodimer is a DNA-binding protein required for heterocyst differentiation, and the DNA-binding activity is inhibited by PatS, Proc Natl Acad Sci USA 101 (2004) 4848-53.

[47] Higa KC, Callahan SM, Ectopic expression of hetP can partially bypass the need for hetR in heterocyst differentiation by Anabaena sp. strain PCC 7120, Mol Microbiol 77 (2010) 562-74.

[48] Videau P, Rivers OS, Hurd K, Ushijima B, Oshiro RT, Ende RJ, O'Hanlon SM, Cozy LM, The heterocyst regulatory protein HetP and its homologs modulate heterocyst commitment in Anabaena sp. strain PCC 7120, Proc Natl Acad Sci USA (2016) pii: 201610533.

[49] Flaherty BL, Johnson DB, Golden JW, Deep sequencing of HetR-bound DNA reveals novel HetR targets in Anabaena sp. strain PCC7120, BMC Microbiol 14 (2014) 255.

[50] Camargo S, Valladares A, Flores E, Herrero A, Transcription activation by NtcA in the absence of consensus NtcA-binding sites in an Anabaena heterocyst differentiation gene promoter, J Bacteriol 194 (2012) 2939-48.

[51] Videau P, Ni S, Rivers OS, Ushijima B, Feldmann EA, Cozy LM, Kennedy MA, Callahan SM, Expanding the direct HetR regulon in Anabaena sp. strain PCC 7120, J Bacteriol 196 (2014) 1113-21.

[52] Kim Y, Joachimiak G, Ye Z, Binkowski TA, Zhang R, Gornicki P, Callahan SM, Hess WR, Haselkorn R, Joachimiak $A$, Structure of transcription factor HetR required for heterocyst differentiation in cyanobacteria, Proc Natl Acad Sci USA 108 (2011) 10109-14.

[53] Valladares A, Flores E, Herrero A, The heterocyst differentiation transcriptional regulator HetR of the filamentous cyanobacterium Anabaena forms tetramers and can be regulated by phosphorylation, Mol Microbiol 99 (2016) 808-19.

[54] Kim Y, Ye Z, Joachimiak G, Videau P, Young J, Hurd K, Callahan SM, Gornicki P, Zhao J, Haselkorn R, Joachimiak A, Structures of complexes comprised of Fischerella transcription factor HetR with Anabaena DNA targets, Proc Natl Acad Sci USA 110 (2013) E1716-23.

[55] Muro-Pastor AM, Valladares A, Flores E, Herrero A, Mutual dependence of the expression of the cell differentiation regulatory protein HetR and the global nitrogen regulator NtcA during heterocyst development. Mol Microbiol 44 (2002) 1377-85.

[56] Black TA, Cai Y, Wolk CP, Spatial expression and autoregulation of het $R$, a gene involved in the control of heterocyst development in Anabaena, Mol Microbiol 9 (1993) 77-84. Erratum in: Mol Microbiol 10 (1993) 1153. 
[57] Olmedo-Verd E, Muro-Pastor AM, Flores E, Herrero A, Localized induction of the ntcA regulatory gene in developing heterocysts of Anabaena sp. strain PCC 7120, J Bacteriol 188 (2006) 6694-9.

763

764

765

766

767

768

769

770

771

772

773

774

775

776

777

778

779

780

781

782

783

784

785

786

787

788

789

790

791

792

793

794

795

796

797

798

799

800

801

802

803

804

805

806

807

808

809

[58] Rajagopalan R, Callahan SM, Temporal and spatial regulation of the four transcription start sites of hetR from Anabaena sp. strain PCC 7120, J Bacteriol 192 (2010) 1088-96.

[59] Muro-Pastor AM, Olmedo-Verd E, Flores E, All4312, an NtcA-regulated two-component response regulator in Anabaena sp. strain PCC 7120, FEMS Microbiol Lett 256 (2006) 171-7.

[60] Ehira S, Ohmori M, NrrA directly regulates expression of hetR during heterocyst differentiation in the cyanobacterium Anabaena sp. strain PCC 7120, J Bacteriol 188 (2006) 8520-5.

[61] Flaherty BL, Van Nieuwerburgh F, Head SR, Golden JW, Directional RNA deep sequencing sheds new light on the transcriptional response of Anabaena sp. strain PCC 7120 to combined-nitrogen deprivation, BMC Genomics 12 (2011) 332.

[62] Valladares A, Rodríguez V, Camargo S, Martínez-Noël GM, Herrero A, Luque I, Specific role of the cyanobacterial PipX factor in the heterocysts of Anabaena sp. strain PCC 7120, J Bacteriol 193 (2011) 1172-82.

[63] Mitschke J, Vioque A, Haas F, Hess WR, Muro-Pastor AM, Dynamics of transcriptional start site selection during nitrogen stress-induced cell differentiation in Anabaena sp. PCC7120, Proc Natl Acad Sci USA 108 (2011) 20130-5.

[64] Llácer JL, Espinosa J, Castells MA, Contreras A, Forchhammer K, Rubio V, Structural basis for the regulation of NtcA-dependent transcription by proteins PipX and PII, Proc Natl Acad Sci USA 107 (2010) 15397-402.

[65] Camargo S, Valladares A, Forchhammer K, Herrero A, Effects of PipX on NtcA-dependent promoters and characterization of the cox3 promoter region in the heterocyst-forming cyanobacterium Anabaena sp. PCC 7120, FEBS Lett 588 (2014) 1787-94.

[66] Brahamsha B, Haselkorn R, Isolation and characterization of the gene encoding the principal sigma factor of the vegetative cell RNA polymerase from the cyanobacterium Anabaena sp. strain PCC 7120, J Bacteriol 173 (1991) 2442-50.

[67] Muro-Pastor AM, Brenes-Álvarez M, Vioque A, A combinatorial strategy of alternative promoter use during differentiation of a heterocystous cyanobacterium, Environ Microbiol Rep 9 (2017) 449-458.

[68] Imamura S, Asayama M, Sigma factors for cyanobacterial transcription, Gene Regul Syst Bio 3 (2009) 65-87.

[69] Khudyakov IY, Golden JW, Identification and inactivation of three group 2 sigma factor genes in Anabaena sp. strain PCC 7120, J Bacteriol 183 (2001) 6667-75.

[70] Aldea MR, Mella-Herrera RA, Golden JW, Sigma factor genes sigC, sigE, and sigG are upregulated in heterocysts of the cyanobacterium Anabaena sp. strain PCC 7120, J Bacteriol 189 (2007) 8392-6.

[71] Ehira S, Ohmori M, NrrA, a nitrogen-regulated response regulator protein, controls glycogen catabolism in the nitrogen-fixing cyanobacterium Anabaena sp. strain PCC 7120, J Biol Chem 286 (2011) 38109-14.

[72] Mella-Herrera RA, Neunuebel MR, Kumar K, Saha SK, Golden JW, The sigE gene is required for normal expression of heterocyst-specific genes in Anabaena sp. strain PCC 7120, J Bacteriol 193 (2011) 182332.

[73] Schrautemeier B, Neveling U, Schmitz S, Distinct and differently regulated Mo-dependent nitrogenfixing systems evolved for heterocysts and vegetative cells of Anabaena variabilis ATCC 29413: characterization of the $f d x H 1 / 2$ gene regions as part of the nif1/2 gene clusters, Mol Microbiol 18 (1995) 357-69.

[74] Saha SK, Golden JW, Overexpression of pknE blocks heterocyst development in Anabaena sp. strain PCC 7120, J Bacteriol 193 (2011) 2619-29.

[75] Huang G, Fan Q, Lechno-Yossef S, Wojciuch E, Wolk CP, Kaneko T, Tabata S, Clustered genes required for the synthesis of heterocyst envelope polysaccharide in Anabaena sp. strain PCC 7120, J Bacteriol 187 (2005) 1114-23. 
[76] Ehira S, Ohmori M, Sato N, Genome-wide expression analysis of the responses to nitrogen deprivation in the heterocyst-forming cyanobacterium Anabaena sp. strain PCC 7120, DNA Res 10 (2003) 97-113.

[77] Zhu J, Kong R, Wolk CP, Regulation of hepA of Anabaena sp. strain PCC 7120 by elements 5 ' from the gene and by hepK, J Bacteriol 180 (1998) 4233-42.

[78] Rippka R, Stanier R, The effect of anaerobiosis on nitrogenase synthesis and heterocyst development by Nostocacean cyanobacteria, J Gen Microbiol 105 (1978) 83-94.

[79] Zhou R, Wolk CP, A two-component system mediates developmental regulation of biosynthesis of a heterocyst polysaccharide, J Biol Chem 278 (2003) 19939-46.

[80] Hagen KD, Meeks JC, Biochemical and genetic evidence for participation of DevR in a phosphorelay signal transduction pathway essential for heterocyst maturation in Nostoc punctiforme ATCC 29133, J Bacteriol 181 (1999) 4430-4.

[81] Ning D, Xu X, alr0117, a two-component histidine kinase gene, is involved in heterocyst development in Anabaena sp. PCC 7120, Microbiology 150 (2004) 447-53.

[82] Fan Q, Lechno-Yossef S, Ehira S, Kaneko T, Ohmori M, Sato N, Tabata S, Wolk CP, Signal transduction genes required for heterocyst maturation in Anabaena sp. strain PCC 7120, J Bacteriol 188 (2006) 6688-93.

[83] Lechno-Yossef S, Fan Q, Ehira S, Sato N, Wolk CP, Mutations in four regulatory genes have interrelated effects on heterocyst maturation in Anabaena sp. strain PCC 7120, J Bacteriol 188 (2006) 7387-95.

[84] Awai K, Lechno-Yossef S, Wolk CP, Heterocyst envelope glycolipids, in: Wada H, Murata N (Eds.) Lipids in Photosynthesis: Essential and Regulatory Functions, Springer Science + Business Media B.V. (2009) pp.179-202.

[85] Fan Q, Huang G, Lechno-Yossef S, Wolk CP, Kaneko T, Tabata S, Clustered genes required for synthesis and deposition of envelope glycolipids in Anabaena sp. strain PCC 7120, Mol Microbiol 58 (2005) 227-43.

[86] Awai K, Wolk CP, Identification of the glycosyl transferase required for synthesis of the principal glycolipid characteristic of heterocysts of Anabaena sp. strain PCC 7120, FEMS Microbiol Lett 266 (2007) 98-102.

[87] Staron P, Forchhammer K, Maldener I, Novel ATP-driven pathway of glycolipid export involving TolC protein, J Biol Chem 286 (2011) 38202-10.

[88] Fiedler G, Muro-Pastor AM, Flores E, Maldener I, NtcA-dependent expression of the $\operatorname{devBCA}$ operon, encoding a heterocyst-specific ATP-binding cassette transporter in Anabaena spp., J Bacteriol (2001) 3795-9.

[89] Muro-Pastor AM, Flores E, Herrero A, NtcA-regulated heterocyst differentiation genes hetC and devB from Anabaena sp. strain PCC 7120 exhibit a similar tandem promoter arrangement, J Bacteriol (2009) 5765-74.

[90] Hebbar PB, Curtis SE, Characterization of $\operatorname{devH}$, a gene encoding a putative DNA binding protein required for heterocyst function in Anabaena sp. strain PCC 7120, J Bacteriol 182 (2000) 3572-81.

[91] Ramírez ME, Hebbar PB, Zhou R, Wolk CP, Curtis SE, Anabaena sp. strain PCC 7120 gene devH is required for synthesis of the heterocyst glycolipid layer, J Bacteriol 187 (2005) 2326-31.

[92] Shi L, Li JH, Cheng Y, Wang L, Chen WL, Zhang CC, Two genes encoding protein kinases of the HstK family are involved in synthesis of the minor heterocyst-specific glycolipid in the cyanobacterium Anabaena sp. strain PCC 7120, J Bacteriol 189 (2007) 5075-81.

[93] Jang J, Wang L, Jeanjean R, Zhang CC, PrpJ, a PP2C-type protein phosphatase located on the plasma membrane, is involved in heterocyst maturation in the cyanobacterium Anabaena sp. PCC 7120, Mol Microbiol 64 (2007) 347-58.

[94] Ermakova M, Battchikova N, Allahverdiyeva Y, Aro EM, Novel heterocyst-specific flavodiiron proteins in Anabaena sp. PCC 7120, FEBS Lett 587 (2013) 82-7. 
[95] Zhao W, Ye Z, Zhao J, RbrA, a cyanobacterial rubrerythrin, functions as a FNR-dependent peroxidase in heterocysts in protection of nitrogenase from damage by hydrogen peroxide in Anabaena sp. PCC 7120, Mol Microbiol 66 (2007) 1219-30.

[96] Valladares A, Maldener I, Muro-Pastor AM, Flores E, Herrero A, Heterocyst development and diazotrophic metabolism in terminal respiratory oxidase mutants of the cyanobacterium Anabaena sp. strain PCC 7120, J Bacteriol 189 (2007) 4425-30.

[97] Allahverdiyeva Y, Isojärvi J, Zhang P, Aro EM, Cyanobacterial oxygenic photosynthesis is protected by flavodiiron Proteins, Life (Basel) 5 (2015) 716-43.

[98] Murry MA, Olafsen AG, Benemann JR, Oxidation of diaminobenzidine in the heterocysts of Anabaena cylindrica, Curr Microbiol 6 (1981) 201-206.

[99] Rubio LM, Ludden PW, Biosynthesis of the iron-molybdenum cofactor of nitrogenase, Annu Rev Microbiol 62 (2008) 93-111.

[100] Haselkorn R, Organization of the genes for nitrogen fixation in photosynthetic bacteria and cyanobacteria, Annu Rev Microbiol 40 (1986) 525-47.

[101] Ungerer JL, Pratte BS, Thiel T, RNA processing of nitrogenase transcripts in the cyanobacterium Anabaena variabilis, J Bacteriol 192 (2010) 3311-20.

[102] Tsujimoto R, Kamiya N, Fujita Y, Transcriptional regulators ChIR and CnfR are essential for diazotrophic growth in nonheterocystous cyanobacteria, Proc Natl Acad Sci USA 111 (2014) 6762-7.

[103] Liang J, Scappino L, Haselkorn R, The patB gene product, required for growth of the cyanobacterium Anabaena sp. strain PCC 7120 under nitrogen-limiting conditions, contains ferredoxin and helix-turnhelix domains. J Bacteriol 175 (1993) 1697-704.

[104] Pratte BS, Thiel T, Homologous regulators, CnfR1 and CnfR2, activate expression of two distinct nitrogenase gene clusters in the filamentous cyanobacterium Anabaena variabilis ATCC 29413, Mol Microbiol 100 (2016) 1096-109.

[105] Tsujimoto R, Kamiya N, Fujita $Y$, Identification of a cis-acting element in nitrogen fixation genes recognized by $\mathrm{CnfR}$ in the nonheterocystous nitrogen-fixing cyanobacterium Leptolyngbya boryana, Mol Microbiol 101 (2016) 411-24

[106] Vernon SA, Pratte BS, Thiel T, Role of the nifB1 and nifB2 promoters in cell-type-specific expression of two Mo nitrogenases in the cyanobacterium Anabaena variabilis ATCC 29413, J Bacteriol 199 (2017) e00674-16.

[107] Jones KM, Buikema WJ, Haselkorn R, Heterocyst-specific expression of patB, a gene required for nitrogen fixation in Anabaena sp. strain PCC 7120, J Bacteriol 185 (2003) 2306-14.

[108] Razquin P, Fillat MF, Schmitz S, Stricker O, Böhme H, Gómez-Moreno C, Peleato ML, Expression of ferredoxin-NADP ${ }^{+}$reductase in heterocysts from Anabaena sp., Biochem J 316 (1996) 157-60.

[109] Valladares A, Muro-Pastor AM, Fillat MF, Herrero A, Flores E, Constitutive and nitrogen-regulated promoters of the petH gene encoding ferredoxin:NADP ${ }^{+}$reductase in the heterocyst-forming cyanobacterium Anabaena sp., FEBS Lett 449 (1999) 159-64.

[110] Bergman B, Lindblad P, Pettersson A, Renström E, Tiberg E, Immuno-gold localization of glutamine synthetase in a nitrogen-fixing cyanobacterium (Anabaena cylindrica), Planta 166 (1985) 329-34.

[111] Tumer NE, Robinson SJ, Haselkorn R, Different promoters for the Anabaena glutamine synthetase gene during groth using molecular or fixed nitrogen, Nature 306 (1983) 337-342.

[112] Valladares A, Muro-Pastor AM, Herrero A, Flores E, The NtcA-dependent P1 promoter is utilized for glnA expression in N2-fixing heterocysts of Anabaena sp. strain PCC 7120, J Bacteriol 186 (2004) 7337-43.

[113] Picossi S, Valladares A, Flores E, Herrero A, Nitrogen-regulated genes for the metabolism of cyanophycin, a bacterial nitrogen reserve polymer: expression and mutational analysis of two cyanophycin synthetase and cyanophycinase gene clusters in heterocyst-forming cyanobacterium Anabaena sp. PCC 7120, J Biol Chem 279 (2004) 11582-92. 
907

908

909

910

911

912

913

914

915

916

917

918

919

920

921

922

923

924

925

926

927

928

929

930

931

932

933

934

935

936

937

938

939

940

941

942

943

944

945

946

947

948

949

950

951

952

953

954
[114] Elhai J, Wolk CP, Developmental regulation and spatial pattern of expression of the structural genes for nitrogenase in the cyanobacterium Anabaena, EMBO J 9 (1990) 3379-88.

[115] Picossi S, Flores E, Herrero A, The LysR-type transcription factor PacR is a global regulator of photosynthetic carbon assimilation in Anabaena, Environ Microbiol 17 (2015) 3341-51.

[116] Herrero A, Stavans J, Flores E, The multicellular nature of filamentous heterocyst-forming cyanobacteria, FEMS Microbiol Rev 40 (2016) 831-854.

[117] Corrales-Guerrero L, Tal A, Arbel-Goren R, Mariscal V, Flores E, Herrero A, Stavans J, Spatial fluctuations in expression of the heterocyst differentiation regulatory gene het $R$ in Anabaena filaments, PLoS Genet 11 (2015) e1005031.

[118] Yoon HS, Golden JW, Heterocyst pattern formation controlled by a diffusible peptide, Science 282 (1998) 935-8.

[119] Corrales-Guerrero L, Mariscal V, Flores E, Herrero A, Functional dissection and evidence for intercellular transfer of the heterocyst-differentiation PatS morphogen, Mol Microbiol 88 (2013) 1093-105.

[120] Zhang L, Zhou F, Wang S, XuX, Processing of PatS, a morphogen precursor, in cell extracts of Anabaena sp. PCC 7120, FEBS Lett 591 (2017) 751-759.

[121] Khudyakov I, Wolk CP, hetC, a gene coding for a protein similar to bacterial ABC protein exporters, is involved in early regulation of heterocyst differentiation in Anabaena sp. strain PCC 7120, J Bacteriol 179 (1997) 6971-8.

[122] Corrales-Guerrero L, Flores E, Herrero A, Relationships between the ABC-exporter HetC and peptides that regulate the spatiotemporal pattern of heterocyst distribution in Anabaena, PLoS One 9 (2014) e104571.

[123] Videau P, Rivers OS, Higa KC, Callahan SM, ABC transporter required for intercellular transfer of developmental signals in a heterocystous cyanobacterium, J Bacteriol 197 (2015) 2685-93.

[124] Mariscal V, Nürnberg DJ, Herrero A, Mullineaux CW, Flores E, Overexpression of SepJ alters septal morphology and heterocyst pattern regulated by diffusible signals in Anabaena, Mol Microbiol 101 (2016) 968-81.

[125] Feldmann EA, Ni S, Sahu ID, Mishler CH, Risser DD, Murakami JL, Tom SK, McCarrick RM, Lorigan GA, Tolbert BS, Callahan SM, Kennedy MA, Evidence for direct binding between HetR from Anabaena sp. PCC 7120 and PatS-5, Biochemistry 50 (2011) 9212-24.

[126] Hu HX, Jiang YL, Zhao MX, Cai K, Liu S, Wen B, Lv P, Zhang Y, Peng J, Zhong H, Yu HM, Ren YM, Zhang Z, Tian C, Wu Q, Oliveberg M, Zhang CC, Chen $Y$, Zhou CZ, Structural insights into HetR-PatS interaction involved in cyanobacterial pattern formation, Sci Rep 5 (2015) 16470.

[127] Risser DD, Callahan SM, Genetic and cytological evidence that heterocyst patterning is regulated by inhibitor gradients that promote activator decay, Proc Natl Acad Sci USA 106 (2009) 19884-8.

[128] Khudyakov IY, Golden JW, Different functions of HetR, a master regulator of heterocyst differentiation in Anabaena sp. PCC 7120, can be separated by mutation, Proc Natl Acad Sci USA 101 (2004) 16040-5.

[129] Callahan SM, Buikema WJ, The role of HetN in maintenance of the heterocyst pattern in Anabaena sp. PCC 7120, Mol Microbiol 40 (2001) 941-50.

[130] Corrales-Guerrero L, Mariscal V, Nürnberg DJ, Elhai J, Mullineaux CW, Flores E, Herrero A, Subcellular localization and clues for the function of the HetN factor influencing heterocyst distribution in Anabaena sp. strain PCC 7120, J Bacteriol 196 (2014) 3452-60.

[131] Higa KC, Rajagopalan R, Risser DD, Rivers OS, Tom SK, Videau P, Callahan SM, The RGSGR amino acid motif of the intercellular signalling protein, HetN, is required for patterning of heterocysts in Anabaena sp. strain PCC 7120, Mol Microbiol 83 (2012) 682-93.

[132] Risser DD, Wong FC, Meeks JC, Biased inheritance of the protein PatN frees vegetative cells to initiate patterned heterocyst differentiation, Proc Natl Acad Sci USA 109 (2012) 15342-7. 
[133] Masukawa H, Sakurai H, Hausinger RP, Inoue K, Increased heterocyst frequency by patN disruption in Anabaena leads to enhanced photobiological hydrogen production at high light intensity and high cell density, Appl Microbiol Biotechnol 101 (2017) 2177-2188.

[134] Liang J, Scappino L, Haselkorn R, The patA gene product, which contains a region similar to CheY of Escherichia coli, controls heterocyst pattern formation in the cyanobacterium Anabaena 7120, Proc Natl Acad Sci USA 89 (1992) 5655-9.

961

962

[135] Liu J, Wolk CP, Mutations in genes patA and patL of Anabaena sp. strain PCC 7120 result in similar phenotypes, and the proteins encoded by those genes may interact, J Bacteriol 193 (2011) 6070-4.

963

964

[136] Liu D, Golden JW, hetL overexpression stimulates heterocyst formation in Anabaena sp. strain PCC 7120, J Bacteriol 184 (2002) 6873-81.

965

966

[137] Bastet L, Boileau C, Bédu S, Janicki A, Latifi A, Zhang CC, NtcA regulates patA expression in Anabaena sp. strain PCC 7120, J Bacteriol 192 (2010): 5257-9.

[138] Orozco CC, Risser DD, Callahan SM, Epistasis analysis of four genes from Anabaena sp. strain PCC 7120 suggests a connection between PatA and PatS in heterocyst pattern formation, J Bacteriol 188 (2006) 1808-16.

970

971

[139] Lynn ME, Bantle JA, Ownby JD, Estimation of gene expression in heterocysts of Anabaena variabilis by using DNA-RNA hybridization, J Bacteriol 167 (1986) 940-6.

[140] Xu X, Elhai J, Wolk CP, Transcriptional and developmental responses by Anabaena to deprivation of fixed nitrogen, in: Herrero A, Flores E (Eds.) The Cyanobacteria: Molecular Biology, Genomics and Evolution, Caister Academic Press, Norfolk, UK (2008) pp. 383-422.

975 
976 Table 1. DNA-binding transcription factors in heterocyst differentiation and function.

\begin{tabular}{|l|c|l|}
\hline Transcription factor & Anabaena ORF & \multicolumn{1}{|c|}{ Characteristics } \\
\hline NtcA & alr4392 & $\begin{array}{l}\text { CRP-family transcriptional regulator. Global } \\
\text { transcription factor that mediates the cellular } \\
\text { responses to changes in the C-to-N balance. } \\
\text { Binds 2-oxoglutarate. }\end{array}$ \\
\hline HetR & alr2339 & $\begin{array}{l}\text { Novel type of transcription factor absolutely } \\
\text { required for heterocyst differentiation. } \\
\text { Inhibited by the PatS morphogen. }\end{array}$ \\
\hline NrrA & all4312 & $\begin{array}{l}\text { OmpR-family two-component response } \\
\text { regulator. Induced by NtcA, it seems to } \\
\text { mediate some NtcA responses. }\end{array}$ \\
\hline DevH & alr3952 & $\begin{array}{l}\text { CRP-family transcriptional regulator. Needed } \\
\text { for transcription of some genes encoding } \\
\text { heterocyst glycolipid-biosynthesis proteins. }\end{array}$ \\
\hline CnfR (a.k.a. PatB) & all2512 & $\begin{array}{l}\text { 2x [4Fe-4S]-binding protein and Xre family } \\
\text { transcriptional regulator. Needed for nif gene } \\
\text { expression. }\end{array}$ \\
\hline
\end{tabular}

978 
982 Figure 1. Filaments and heterocysts of Anabaena sp. strain PCC 7120. (A) Filaments consisting 983 of vegetative cells and heterocysts. Black arrows, intercalary heterocysts; white arrow, terminal 984 heterocyst. Micrograph by J. E. Frías (CSIC, Seville). (B) Transmission electron micrograph of a 985 terminal heterocyst and adjacent vegetative cells. The honeycomb membranes, the heterocyst 986 polysaccharide (Hep) layer and, just beneath the Hep layer, the heterocyst glycolipid (Hgl) layer 987 are indicated. CG indicates the place of localization of the cyanophycin granule (at the 988 heterocyst pole, next to the heterocyst "neck"), which is frequently lost during sample 989 preparation. Carboxysomes are readily observed in vegetative cells. Micrograph courtesy of I. Maldener (Universität Tübingen).

991

Figure 2. Crystal structures of NtcA from Anabaena (A) and of HetR from Fischerella (B), and example of a heterocyst differentiation gene promoter region, that of the $\operatorname{dev} B C A$ promoter from Anabaena (C). The NtcA dimer contains one molecule of 2-oxoglutarate bound (black arrow), and the HetR dimer is bound to a 24mer DNA target (bottom) and has also bound one $\mathrm{Mg}^{2+}$ ion (black arrow). Structures from Protein Data Bank in Europe (PDBe), number 3 la7 (NtcA [39]) and number $4 \mathrm{j} 00$ (HetR [54]). (C) The $\operatorname{dev} B C A$ operon is transcribed during heterocyst differentiation from two promoters, a distal Class II NtcA-dependent promoter that is independent of HetR, and a proximal NtcA- and HetR-dependent promoter that bears an imperfect NtcA-binding site but is activated by NtcA with a positive effect of HetR [50]. Orange boxes, -10 promoter hexamers; solid green box, consensus NtcA-binding site; hatched green box, degenerated NtcA-binding site.

Figure 3. General scheme of transcriptional activation during heterocyst differentiation including a selected set of target genes as examples. The process takes about 18 to $24 \mathrm{~h}$ to complete after $\mathrm{N}$ step-down, depending on lab conditions. Although no precise times are intended in the scheme, the genes presented left to right correspond to genes expressed early to late in the process. The left part of the scheme shows the NtcA-NrrA-HetR interactions. Grey central boxes include groups of genes involved in the indicated activities (hetC is included in pattern formation because of its proposed role in PatS transfer). The upper part captures the

1011 extensive direct regulation exerted by NtcA. Three examples of direct regulation by HetR are 1012 indicated in the lower-left part. Below the central boxes, other regulators that influence 1013 transcription, including regulators that may respond to $\mathrm{O}_{2}$, are shown. Block arrows represent 
1014 the indicated genes. Other shapes (ovals, squares, triangles, etc.) represent proteins.

1015 Abbreviations: HK, histidine kinase; RR, response regulator; STK, serine/threonine kinase; HTH,

1016 helix-turn-helix motif; -P, demonstrated or possible phosphorylation. Solid arrows represent

1017 direct regulation (i.e., demonstrated binding of the regulator to a promoter), dotted arrows

1018 represent possible or hypothetical direct regulation, and dashed arrows indicate indirect

1019 regulation or an unknown mechanism.

1020

1021 Figure 4. Hypothetical model of PatS production and intercellular transfer in Anabaena. The patS

1022 gene is induced at the beginning of heterocyst differentiation dependent on NtcA and HetR,

1023 producing a polypeptide (PatS) that is processed to render the active morphogen (PatS*). The

1024 peptidase/ABC exporter HetC appears necessary for PatS function; because PatS* does not

1025 accumulate in (pro)heterocysts, it can be suggested that it is actively exported from them. On

1026 the other hand, SepJ appears to be involved in the transfer of PatS* between vegetative cells

1027 suggesting transfer through the septal junctions. The activity of PatS* as a negative regulator of

1028 HetR is represented.

1029 

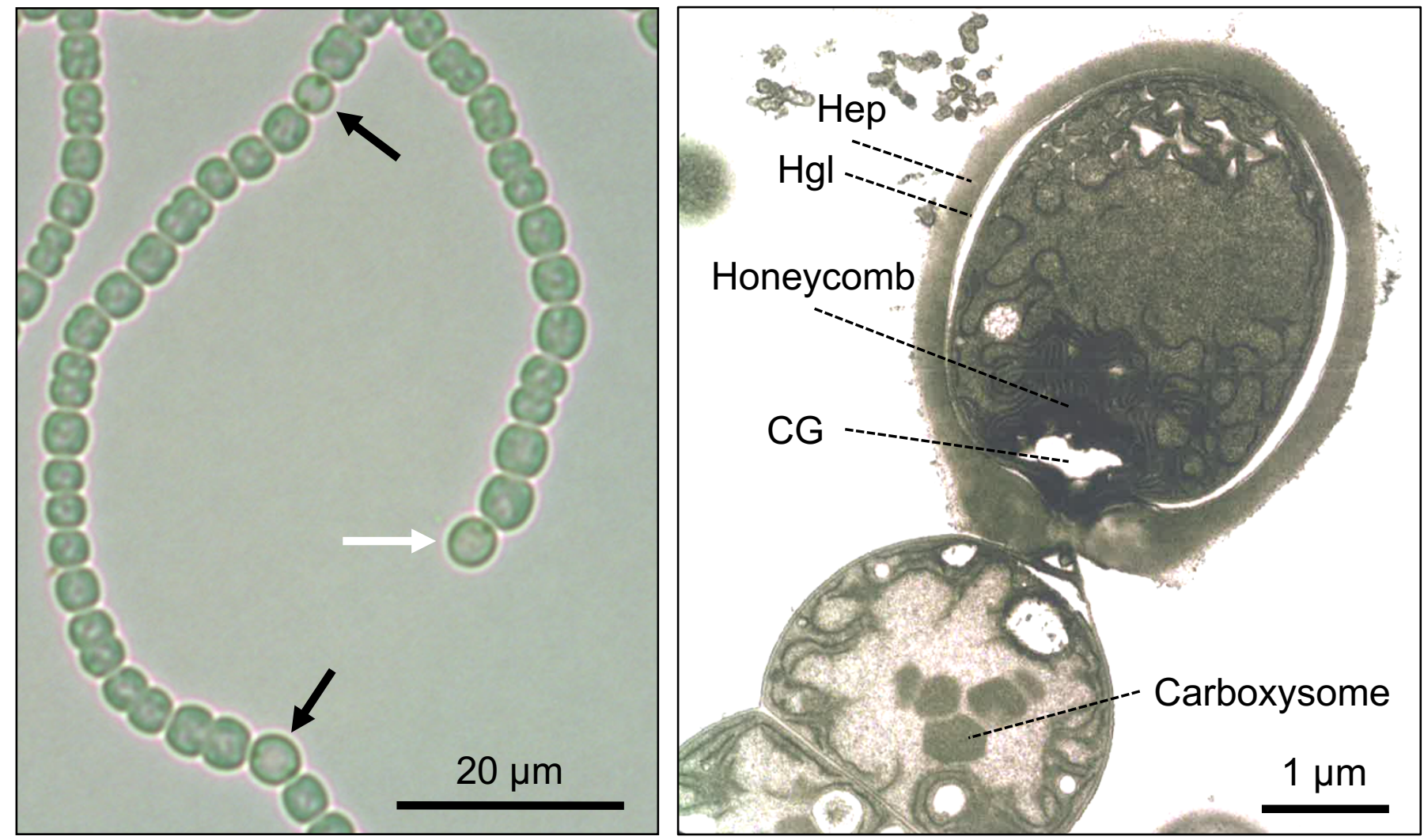

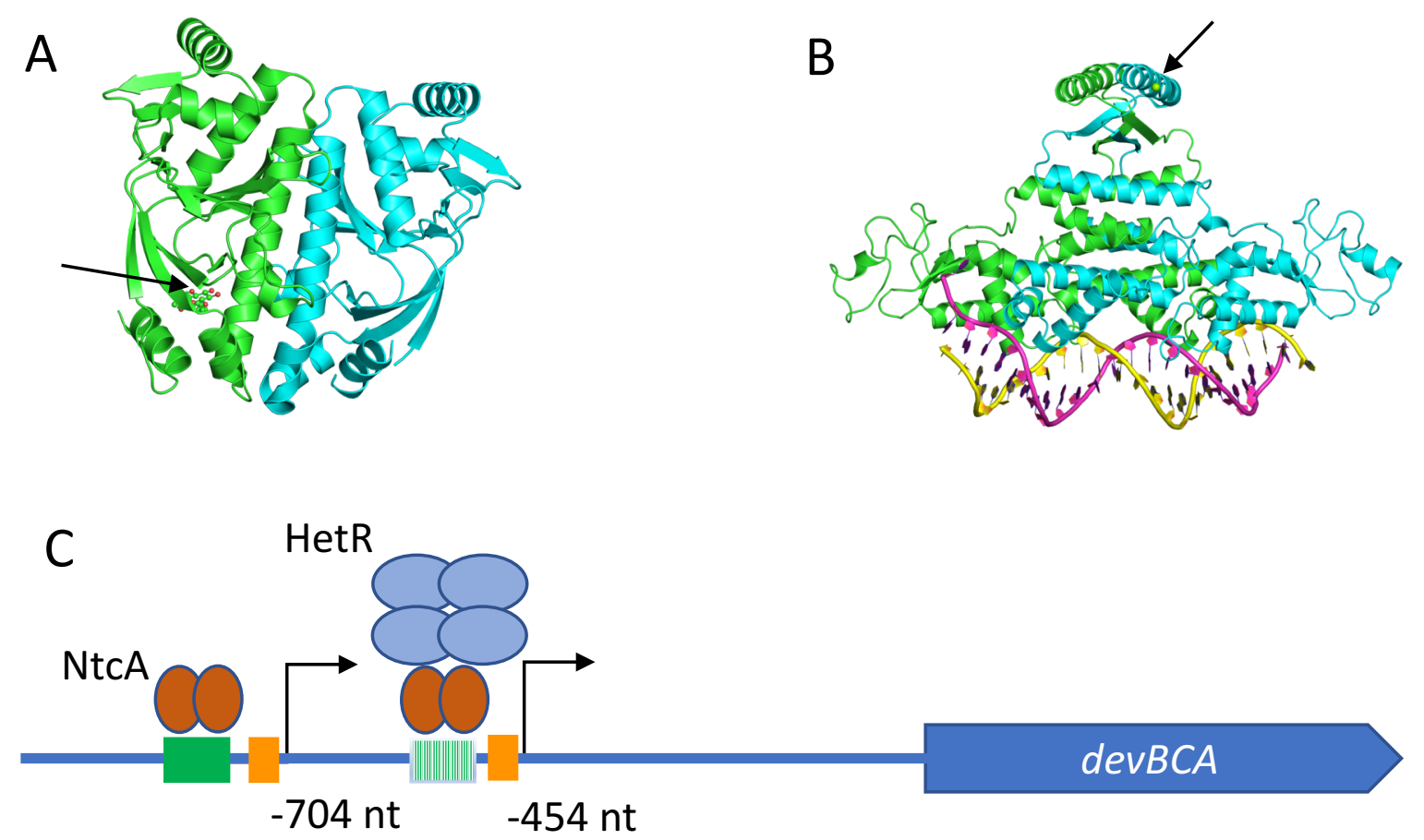

$\operatorname{dev} B C A$ 


\section{$-\mathrm{N}$ (high $\mathrm{C} / \mathrm{N}$ )}

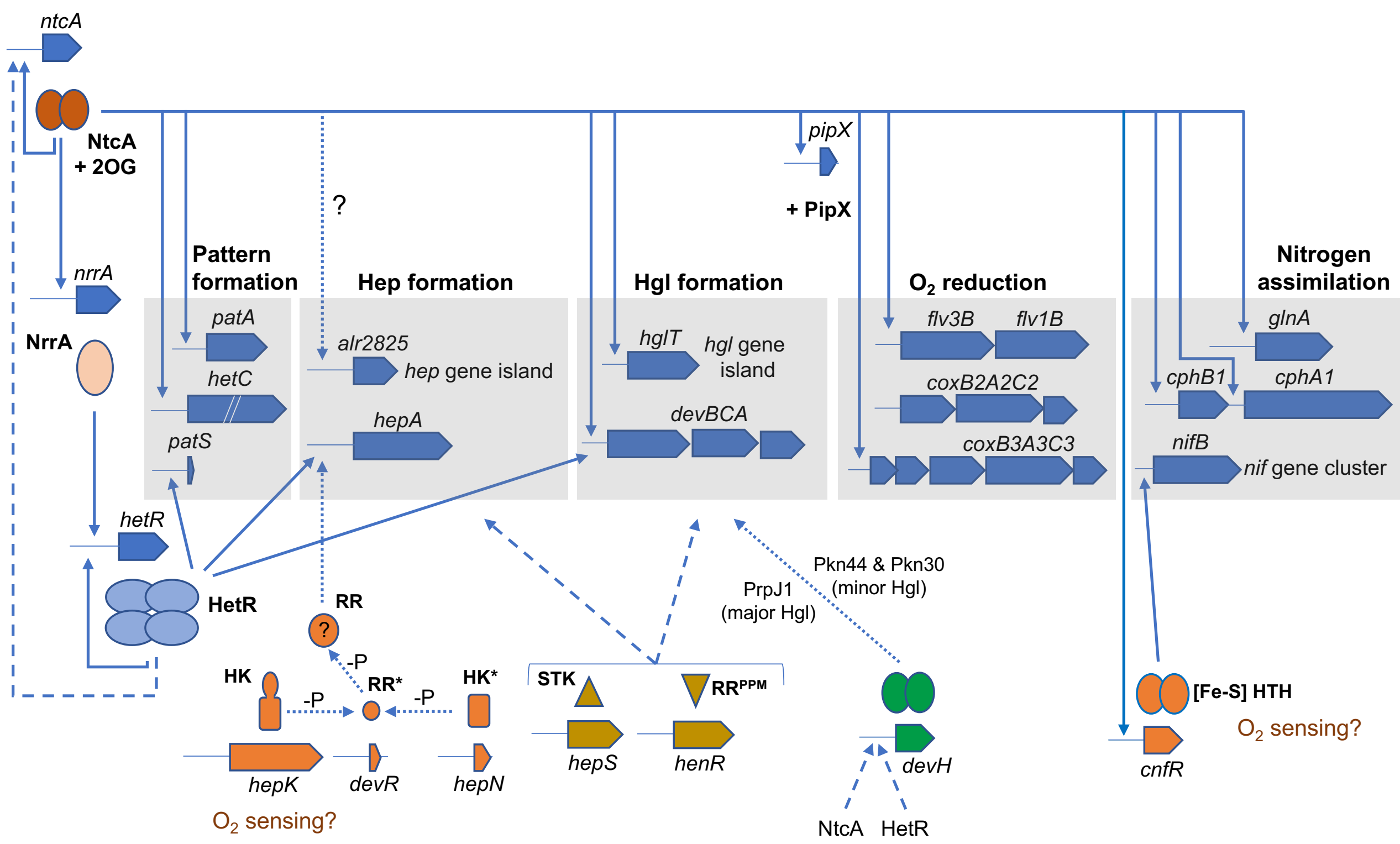




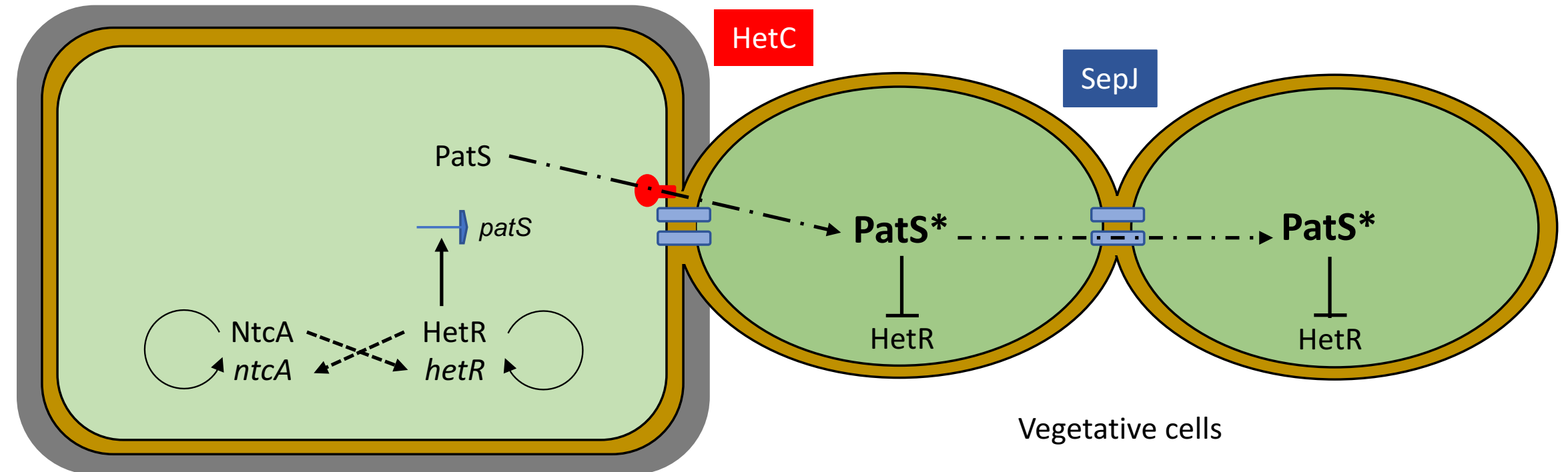

(Pro)heterocyst 